\title{
The Towering Tree
}

\author{
El árbol imponente
}

\author{
Mónica JimÉnez AgUiLAR \\ Bachillerato en Inglés \\ Universidad de Costa Rica
}

$\mathrm{M}$ y barefoot carcass moves through the road. That soft road with harmless stones that the emerald moss suffocates. The shapeless figures in the sky restrain the light from touching the ground; the shimmering wind dances inside the forest and it rests when it touches the treetops. The trees protect the road with a hug that forms an arch along the way.

White clothes cover my body as my feet kiss the colors I'm immersed in; a golden necklace with a seal that bears no letters rests in my chest; my hair are brown leaves that float untamed in the breeze. My eyes touch every shape in the distance, but my mind is numb and quiet while all the colors run freely. A towering tree cuts the road; its branches hold the weight of the sky, and the flickering green leaves fall from their grace to the soil with such majesty that eyes may mistakenly perceive them as glittering emeralds, garnets, and jades.
Void is the center of the towering tree for a frame with no door reveals an entrance which I carefully approach. My reluctant feet take slow steps; this place appears to me just like an enormous water swirl that could swallow the ocean. It's beauty and majesticity become hypnotic and inviting.

Inside, spiral stairs run beneath the ground as they fulfill the roots beyond my sight. I can feel the warmth of the tree with my hands, but the cold wind flies through me like the water flows through ice. The internal structure of the tree continues from miles and the different paths remain separated from each other. The hand of nature played the role of architect for the roots of the tree shape the walls, and the soil embodies the stairs. Several chambers are reachable through hallways; small circular rooms with miniature round windows up on the wall are a portal to the never ending falling of the leaves. 
The chambers remain hollow with the exception of the rectangular beddings that are made of soil and moss. I visit every chamber; all of them are connected between them. I can feel my arms getting warmer as I descent through the path within the tree; the breath that I missed, and the sense of closeness comeback little by little. I found myself playing along the corridors; I move as the stairs flow beneath the surface and as they enter deeper and deeper inside the tree. I lack the reminiscence of a previous home, but this place gives me the closest feeling to comfort that I can imagine; some people would even consider this atmosphere as harmonious and quiet. My feet stop their motion and now I am part of one of the chambers; my eyelids are heavy; my body is a stone, and so, I lay in a bedding close to me.

The cry of a woman washes my dreams; I stand up from rest and I clear my sight. I stare at my legs in disbelief for tiny pieces of moss have started to grow in my skin. How deep my dreams have been! I nervously take off the plants from my body, and now I feel anxious... and lonely... and frightened. All of the sentiments that I had forgotten come back to me as if I'm drowning. I run through the corridors barefoot while I seek for the source of the sound. Desperately, I look for warmth, a home, a word; I look for someone. I finally found a woman and her tears clean the bedding of one of the chambers. Cautiously, I stay near the arch of the room; but her eyes never lay on me. I want her to touch me, so she can give me a name... so she can clean my tears... so she can take me with her... so she can make me someone. But she does not. She rises from the floor as she leaves white lilies in the bedding. She wears a black suit with horizontal white stripes on the sleeves; a wide brim hat with the same colors shelters her raven locks. I remain unnoticed as she weeps profusely; why does she cry? Perhaps her husband is here, or her children. This is a place where people forget. They forget about their lives; this is the place where we dream about roots, and moss, and flowers, and leaves falling from grace.

My placement here is uncertain. How I got here I cannot recall; is my family here? Someone awaits for me? Should I cry for someone? Should someone cry for me? My feet create my path, but some distances cannot be reached alone. Is it true that I am far away from home? I cannot recall. I do not remember wearing this dress before, or that I own it at all. Questions eat me from inside out for I dedicate myself to feel this place but not to think about it. I fall upon its mystery and I do not fight back; that goes against my desires. The warmth of the roots claimed me.

The woman's steps take her outside the tree; she takes her grief with her, and her lack of sight for see me; she cannot hear me, nor perceive me. She walks close to me with those long and weak legs. My mind becomes silent again, but it is not longer cold. Questions no longer feed on me; I just watch her steps flowing in the path as if it was made of air. I catch her scent; I hunt it. She walks away with everything that I desire deeply, but how would she take me? How would she name me? I already have a name. The expression on her face; the shadows under her eyes. She crosses the road of emerald moss as I stay here in the tree arch. This is my home now. Everything I was before 
coming here exists no more. The impossibility of my desires makes them a burden. Chasing shadows is useless for shadows are nowhere to be found.

The horizon swallows the woman as I decide to enter the tree one more time. I kiss the tree with my feet as I walk, and I place myself under the stairs where the sunshine penetrates the little round windows, but how can the sun reach here when fog reigns above? The birds sing as if their music was a secret until this moment.
Resting in my chest, a golden necklace with a seal that reads "Omni." The moss in my little bedding seems soft and inviting, and some flowers are now blooming from the moss. The sweet and happy laughter of women, men and children starts filling the corridors with such joy! Such a beautiful place! And so mine! My eyelids feel heavy, but my rest is nowhere near for I am the scent of this forest and I will always be. 
